\title{
Civil strife and economic and social policies
}

Joseph E. Stiglitz

$\mathrm{T}$ he issue of civil strife and economic and social policies is one I became engaged with while working at the World Bank. It is of tremendous importance, particularly in sub-Saharan Africa. The last 50 years have shown that development is possible, but far from inevitable. Fifty years ago, as many of the economies in the developing world were becoming independent, there was great hope for their success. In the half century that has gone by we have seen that one region in the world, East Asia, has had huge success in terms of per capita income (in countries like Korea, an eight-fold increase), but in many other parts of the world, such as sub-Saharan Africa, there has been by and large enormous failure. Incomes today in much of sub-Saharan Africa are lower than they were 20 or 30 years ago. Life expectancy, after increasing substantially over a number of years, now has begun to decline, mainly but not only because of the AIDS epidemic.

\section{Conflict and underdevelopment}

The question of why has there been such success in East Asia and why has there been such failure in sub-Saharan Africa has many dimensions. One of the most important is the issue of civil strife, which has plagued much of the region for the last thirty years. An example lies in the contrast between Botswana and Sierra Leone. Botswana and Sierra Leone are both rich in diamonds, but in Botswana, diamonds have been used to raise standards of living; in Sierra Leone they have been the source of civil strife and its people have become worse off.

\begin{abstract}
Without wishing to sound inhumane, for economists the large number of civil conflicts does have one major advantage: we can study the causes of strife.
\end{abstract}

Indeed of the ten poorest countries of the world, six have suffered civil war in recent years. Civil wars are a major contributor to poverty. In 1999, in contrast to two international conflicts there were 25 civil conflicts around the world, a staggering number. Without wishing to sound inhumane, for economists the large number of civil conflicts does have one major advantage: we can study the causes of strife. The terrible suffering does at least give us a rich enough data set that we can try to understand which factors cause strife and which extend strife's duration. The result has been the beginning of work, particularly at the World Bank, trying to identify these factors.
Here I address several of the more important factors, particularly from a theoretical perspective. ${ }^{1}$ There is a two-way relationship between civil strife and economics. I referred to the fact that civil strife leads to poverty, but it is also true that poverty and economic stagnation are a major cause of civil strife. This fact was brought home forcefully in the case of Indonesia where the 1997 East Asian currency crisis resulted in a dramatic fall in incomes and a dramatic increase in unemployment. In developed economies we talk about an economic downturn in terms of, say, a two percent decrease in GDP. But in Indonesia, the fall in GDP was 16 percent, and real wages of many of the poorest workers went down by 25 to 30 percent. Unemployment increased ten-fold. In the middle of this process - falling GDP, falling real wages, rising unemployment - and under the influence of the International Monetary Fund (IMF), food and fuel subsidies were cut for the poor. The consequence, one the IMF was warned of five months previously, was perfectly predictable: riots broke out and further weakened the economy. Had the IMF pursued a less contractionary policy, it could have avoided the civil strife. Had it avoided the civil strife, it could have minimized the magnitude of the downturn the people faced.

Imperfect information: an analogy between strife and strike

Strife can be seen as an extreme form of breakdown of society and its economy. In many ways it is like a conflict between employer and employees, a strike. One would think that rational people could resolve their disputes in ways that do not lead to massive misallocations of resources. But what happens in a strike is an unnecessary idleness of both labor and machines, so that the strike represents a breakdown in industrial relations. The employer believes that the worker cannot manage to survive without wages, and the worker believes that the firm will not be able to survive the loss of profits from the strike. The prospect of a strike and corresponding lock-out is a mutual threat to impose harm in the hope that one side or the other will give in and a resolution of the impasse will occur.

Theorists spend a lot of time trying to understand why strikes, which seem so inefficient, occur. After all, at the end of the strike there is a resolution: people go back to work, production resumes, wages and profits are restored. Why not skip the intervening period in which resources are inefficiently used? One theoretical approach to this problem is the idea of bargaining under incomplete information. An aspect of such bargaining is that each side tries verbally to convey information to the other, but because "talk is cheap" the information can only really be conveyed through costly mechanisms. The workers say, "We care so much about this issue that we're willing to pay a price.” The employers likewise say, "We care so much about this that we're willing to pay a price.” It is because of the sacrifices that each side makes that the communication, costly as it is, actually takes place.

Civil strife is like a strike: when the two sides in the process cannot reach an 
agreement, there is an impasse. In the end there is a resolution, but before the resolution occurs there is strife, and that strife is costly not only to the people involved, but painfully costly to others in society. Conflicts are often based on a basic, initial misjudgment: each side believes it can win. Obviously, if they had rational expectations, each would realize it is not possible for both sides to win, and that the net gain they obtain after the strike is less than they could have got if they had settled before the strike. One of the characteristics of conflicts is they are based on a fundamental misjudgment about the relative positions of the two sides. These imperfections of information lie at the core of much civil strife.

\section{Some causes of civil strife}

Apart from imperfect information, which other factors help determine the benefits and cost of cooperation versus the benefits and cost and conflict? One factor, and this is true both theoretically and empirically, is whether the economy is essentially a rent economy or an economy involved in real productive activity. A rent economy is an economy like Angola's, dominated by diamonds and oil, where people basically are sitting on a pile of money and little real production is occurring. ${ }^{2}$ The Angolan economy does not add value to these commodities through processing or manufacturing. The question is who is going to get what share of the pile of money; how will the pie be divided?

One way of thinking about dividing the pie of a natural resource-based economy is as a zero-sum game: the more I get the less you get. This almost naturally leads to conflict. Another useful analogy might come from a child's view of parental love. Two or three siblings compete fiercely for their parents' attention on the view that there is a fixed amount of attention. If one gets more, the other has to get less. Of course, this need not be true in reality. But if the perception is that there is a fixed size of the pie, the only issue that is at stake is how you divide the pie. Thus, conflict is very likely to occur.

\begin{abstract}
One reason conflict is so frequent in Africa is that many of its economies have for so long been rent-based. They have not been based on manufacturing, they have not been based on investment. The pie to be divided does not grow.
\end{abstract}

dividing the spoils among the contestants.

The notion of endemic conflict in rent economies can be contrasted with what happens in an investment economy. In an investment economy, a manufacture and service-based economy, what happens if civil strife occurs? Investment stops. Nobody wants to invest in an economy in which conflict destroys one's capital. Everybody sees large potential losses looming and that there will be nothing to divide once fighting starts. The cost of strife is enormous, and the benefits of continued cooperation are huge also. This contrast illustrates forcefully why civil strife is so common in Africa and so much less common in other parts of the world. In Africa the individual contestant sees huge benefits from seizing as much of the fixed-size pie as he can, but little cost because investment is already low.

A second factor affecting the existence of strife is whether individuals feel they have much to lose by engaging in strife. There are Low income and low mobility contribute to the existence of strife. two aspects to this: income and mobility. Low-income people, already at subsistence level, have relatively little to lose from conflict. In a low-mobility society there is not much to lose from conflict either, because if local wages are low people cannot do any better elsewhere. And in much of Africa both income and mobility are low. Engaging in conflict, therefore, is cheap. Opportunity costs are low, and low income and mobility contribute to the existence of strife.

To bring home this point, consider that a number of people believe that ethnic fractionation is an important contributor to strife, and it does play a role. But the degree of ethnic fractionation in some European countries, for instance Belgium, is not all that different from that of many African countries. What differentiates the two situations is the level of income and mobility and given strata of the ethnic fractionation.

A third factor is whether the economy functions as an one-round game or as a repeated game. If society is already dissolving, the kinds of things that ordinarily glue people together - repeated interactions in the market, shared customs, and the expectations and trust built thereon - are weakened. Interactions become "one-offs." Consequently, the incentives for conflict are increased, as is the cost of cooperation.

Finally, a fourth and crucial factor has to do with voice and disenfranchisement. If there is a group within society that believes its voice is not heard, that its concerns are not or will not be reflected in the collective decisions made by society, that group has little to lose by conflict and is therefore more likely to engage in it.

Let me emphasize that what is of relevance is not just the reality of these various factors but also peoples' perceptions of them. Consider the Indonesian crisis of the late 1990s: the fact that Indonesia experienced ethnic strife thirty years earlier contributed to its sense of continued insecurity. Had it not had that experience it might have been possible to avoid the strife in the most recent episode. In short, history matters. 
Political and social implications

The story of Indonesia contains an important message: think very hard about policies that might cause strife because it may be difficult to reverse the consequences.

(n)
matters and cannot be undone. Certain policies were adopted in Indonesia that led to the civil strife of 1998. Indonesians cannot say, as the IMF did right after the riots broke out: "Oh, we made a mistake. We will put the subsidies back into place. We didn't really need to abolish those subsidies. That was wrong." Unfortunately, there is a time-line to history. When one restores the subsidies, one does not thereby undo the damage. The resulting ethnic strife and civil disharmony is now part of the reality that the people of Indonesia will have to deal with for decades to come. The story of Indonesia contains an important message for makers of economic policy: think very hard about policies that might cause strife because if you do engage in those policies, it may be difficult to reverse the consequences. The Indonesian example urges extreme caution in policies that carry those potential effects.

Second, I wish to address the topic of democracy and strife. I referred before to the role of disenfranchisement. When people feel that their voice is not being heard, they are more likely to engage in strife. Sometimes people believe that "Democracy is all we need.” Democracy, in its simplest version, means going to the ballot box and making sure that the majority rules. But being able to cast a ballot is not enough to avoid civil strife. With voting it is possible to arrive at a democratically legitimized tyranny of the majority over a minority. A democracy may wind up, in spite of voting, with strife. We have seen a number of instances of that kind. The ballot box does not guarantee that all groups can be heard.

Many societies in which government does not use the ballot box are very well attuned to this point. Many of us prefer democracy, of course; I certainly do myself. But it is nonetheless true that in countries where people do not go to the ballot box, leaders have to look for other forms of legitimization, and those other forms of legitimization entail, in part, ensuring that all groups' voices are heard. Ironically, in some countries in which the ballot box is not used, there is more sensitivity to ensuring that the voices of minorities are heard.

This assurance can be derived through a variety of mechanisms. In many countries the recognition of the possibility of the "tyranny of the majority" has led to explicit introduction of restrictions on what the majority (through a duly elected government) can do. In the United States, for example, there is the Bill of Rights. The Bill of Rights - freedom of the press, freedom of religion, freedom of speech, even privacy rights - are rights that a majority of voters cannot remove from the minority of voters.

Ethiopia uses a different mechanism. Its recently adopted constitution gives any region the right to withdraw from the country. Now why would the framers do that, if they did not intend to have the country break apart? By giving the right to each region to withdraw, Ethiopia ensures that the central government pays attention to the concerns of the regions. For the last decade this framework has been working fairly effectively and is an interesting experiment in ensuring voice.

Empirically, it appears that societies with a high degree of ethnic fractionation enjoy greater stability than countries in which there is little, and particularly more than those countries which have only two main groups. With large numbers of groups one sees shifting alliances which minimize the opportunities for one group to dominate another. A variety of possible alliances lead to greater stability. I want to emphasize that for democracy to really be effective, and to generate a sense of enfranchisement to avoid civil strife, one has to engage in meaningful processes that include consensus building and sharing of information. Several countries have instituted these kinds of processes and as a result have achieved a higher degree of stability.

The third point that I want to emphasize is that it is not just equality that matters, but mobility as well. The perceived option of upward mobility, the sense of having a chance to do better, is very important in maintaining social stability. The fourth point is that economic growth matters. The kind of policies that led to stagnation and decline, as we have seen in Indonesia, entail a downward spiral effect. As growth declines social cohesion declines and that leads to more strife which, in turn, leads to further decline.

My fifth point relates to efforts to expand the scope of cooperation among society's members. There are essentially two ways through which cooperation can be expanded. One is through legal systems in which one coerces people to behave cooperatively, if necessary by threat of force (the "law and order" function of police forces). The other way is through the use of incentives or rewards, to convince people that it is in their interest to cooperate and avoid strife. The problem facing much of sub-Saharan Africa is that its states are so weak that one of the basic functions of the state - to enforce cooperative behavior by policing - is missing. Regrettably, a system of incentives for cooperation is also missing. Both the guarantees of cooperation, the carrots and the sticks, are missing, and as a result the incidence of strife is high.

The sixth and final point regards the importance of trying to create a sense of national identity, i.e., the forging of social capital, and the role of social capital in bringing people into cooperative action. In the theory of economic organization, we 
talk about how one gets people to act cooperatively. One way is to provide incentives, but incentives can be very difficult to provide.

An alternative way is to change peoples' beliefs and perceptions and try to get them to identify with the organization. In economics today we often make use of the concept of "social capital" through which people gain a sense that they belong to a common society. An unfortunate example of the destruction of social capital comes from Russia. The last decade in Russia has been dismal: output has declined by 50 percent, and the population has gone from two percent in poverty to 50. One of the most convincing explanations proffered has to do with the destruction of social capital that coincided with the rapid shift to a privatized, market economy.

Several countries have tried deliberately to create a strong sense of social capital by making people have an explicit notion of a social contract, an explicit attention to social justice, much more awareness of a common history, common language, and common culture. On the whole, societies in Asia are much less riven by strife than societies in Africa and some economists ascribe this in part to a greater stock of social capital.

\section{Conclusion}

Civil strife and the implications for economic and social policy illustrates how economics is becoming redefined. It is becoming redefined both in the questions that we ask and the tools that we use to answer those questions. But in trying to understand society and even its economic behavior, we have to go beyond the narrow confines of traditional economics. I believe that economics is an important tool for understanding how we can help create a better society and lessen civil strife. Trying to understand the factors that have contributed to civil strife, trying to design policies that will avoid the likelihood of civil strife is essential because, as mentioned at the outset, civil strife is one of the most important factors that is impeding economic growth in sub-Saharan Africa and much of the rest of the world and has led to so much poverty in so many countries around the world. Unless we address the factors contributing to civil strife, we cannot hope to have these countries share in the potential benefits that can come from the process of globalization that has become so central to the world today.

\section{Notes}

Joseph E. Stiglitz is professor of economics at Columbia University, New York City, New York, USA.

1. Paul Collier, in this issue, summarizes some of the available empirical findings.
2. For the story of Angola, see Manuel Ennes Ferreira's article in this issue. Also see David Gold's article, in this issue, on conflict diamonds. 